Quim. Nova, Vol. 35, No. 7, 1474-1476, 2012

\title{
A BRIEF INTRODUCTION TO MOLECULAR ORBITAL THEORY OF SIMPLE POLYATOMIC MOLECULES FOR UNDERGRADUATE CHEMISTRY STUDENTS
}

\author{
Ione M. Baibich* \\ Instituto de Química, Universidade Federal do Rio Grande do Sul, Av. Bento Gonçalves 9500, 91501-970 Porto Alegre - RS, Brasil \\ Ian S. Butler \\ Department of Chemistry, McGill University, 801 Sherbrooke St. West, Montreal, Quebec, Canada H3A 2K6
}

Recebido em 18/7/11; aceito em 14/2/12; publicado na web em 15/6/12

\begin{abstract}
A simple, four-step method for better introducing undergraduate students to the fundamentals of molecular orbital (MO) theory of the polyatomic molecules $\mathrm{H}_{2} \mathrm{O}, \mathrm{NH}_{3}, \mathrm{BH}_{3}$ and $\mathrm{SiH}_{4}$ using group theory is reported. These molecules serve to illustrate the concept of ligand group orbitals (LGOs) and subsequent construction of MO energy diagrams on the basis of molecular symmetry requirements.
\end{abstract}

Keywords: molecular orbital theory; ligands group orbitals; molecular symmetry.

\section{INTRODUCTION}

Undergraduate students often have great difficulty understanding the molecular orbital (MO) theory for non-linear, polyatomic molecules. Most inorganic chemistry textbooks address the MOs of simpler polyatomic molecules without using molecular symmetry or group theory. Typically, only in later chapters of textbooks is the concept of ligand group orbitals (LGOs) and application of group theory in the MO approach introduced, and even then chiefly for transition metal compounds. ${ }^{1-5}$ To better appreciate LGOs, it is important to understand that the orbitals of the ligands cannot be treated independently, because they transform under the symmetry operations of the molecular point group concerned. We describe here a relatively straight-forward, stepwise method by which undergraduate students can better understand the benefits of MO theory in inorganic chemistry. Nowadays, in many universities throughout the world, undergraduate students are introduced to group theory on physical chemistry courses before embarking on inorganic chemistry courses.

\section{RESULTS AND DISCUSSION}

We are assuming here that the students understand the principles of point group symmetry and know how to identify the basic symmetry elements for a molecule: principal rotation axis and other rotation axes, planes of symmetry, center of symmetry (or inversion center), rotation-reflection axes and identity. In addition, we assume that students know how to classify a molecule according to its particular point group and are aware that irreducible representations represent the symmetries of specific molecular properties, in our case, the valence orbitals. ${ }^{6}$ It is also assumed that the basic principles of molecular orbital (MO) theory for diatomic molecules which students have seen in earlier courses are understood along with the fact that molecular orbitals are linear combinations of atomic orbitals. These linear combinations occur when the symmetries of the atomic orbitals are the same and the orbitals are close in energy. Finally, the students are taken to fully understand the differences between bonding, antibonding and nobonding molecular orbitals. Four representative polyatomic molecules will be considered in this paper, namely: $\mathrm{H}_{2} \mathrm{O}$, $\mathrm{NH}_{3}, \mathrm{BH}_{3}$ and $\mathrm{SiH}_{4}$.

*e-mail: ione@iq.ufrgs.br

\section{Example 1: $\mathrm{H}_{2} \mathrm{O}$}

The point group of $\mathrm{H}_{2} \mathrm{O}$ is $\mathrm{C}_{2 v}$. The symmetries of the valence orbitals of the central $\mathrm{O}$ atom can readily be obtained from the $\mathrm{C}_{2 \mathrm{v}}$ character table. The symmetries of $s$ orbitals are always given by the totally symmetric irreducible representations in character tables, while symmetries of $p$ orbitals are obtained from the $3^{\text {rd }}$ column of the character tables in which the $x, y$ and $z$ Cartesian coordinate axes are indicated. The $d$ orbitals can be identified from the $4^{\text {th }}$ column of the character tables as the binary products of the Cartesian coordinates $\left(z^{2}, x y\right.$, etc.). To obtain the symmetries of the LGOs of $\mathrm{H}_{2} \mathrm{O}$, we need to know that the $\mathrm{C}_{2}$ principle rotation axis is about the $z$-axis containing the $\mathrm{O}$ atom. In order to find the reducible representations for the LGOs, the following well-known group theoretical reduction formula is used:

$$
\mathrm{a}_{\mathrm{i}}=\frac{1}{\mathrm{~h}} \sum_{\mathrm{R}} \mathrm{g} \mathrm{X}_{\mathrm{i}}(\mathrm{R}) \mathrm{X}_{\mathrm{t}}(\mathrm{R})
$$

where $\mathrm{a}_{\mathrm{i}}$ is the number of times the $i$-th irreducible representation appears in the reducible representation, $\mathrm{h}$ is the order of the group, $\mathrm{R}$ represents the symmetry operation, $g$ is the order of the class, $X_{i}(R)$ is the irreducible representation character in $R$ and $X_{t}(R)$ is the reducible representation or total representation character in $\mathrm{R}$. The orbitals that are going to combine linearly must have the same symmetry and be close in energy. The actual energy levels for individual molecules are readily obtained from experimental measurements, such as by photoelectron spectroscopy.

For $\mathrm{H}_{2} \mathrm{O}$, we therefore have:

$\underline{\text { Step } 1}$. Identification of the point group symmetry of the molecule: $\mathrm{C}_{2 \mathrm{v}}$ Step 2. Determination of the symmetries of the valence orbitals of the central atom.

From the $\mathrm{C}_{2 \mathrm{v}}$ character table (Table 1), the $s$ valence orbital has $\mathrm{a}_{1}$ symmetry, while the symmetries of the $p$ valence orbitals are

Table 1. $C_{2 v}$ character table

\begin{tabular}{ccccccc}
\hline$C_{2 v}$ & $\mathrm{E}$ & $\mathrm{C}_{2}$ & $\sigma_{\mathrm{v}}(\mathrm{xz})$ & $\sigma_{\mathrm{v}}^{\prime}(\mathrm{yz})$ & & \\
\hline $\mathrm{A}_{1}$ & 1 & 1 & 1 & 1 & $z$ & $x^{2}, y^{2}, \mathrm{z}^{2}$ \\
$\mathrm{~A}_{3}$ & 1 & 1 & -1 & -1 & $R_{z}$ & $X y$ \\
$\mathrm{~B}_{1}$ & 1 & -1 & 1 & -1 & $x, R_{y}$ & $X z$ \\
$\mathrm{~B}_{2}$ & 1 & -1 & -1 & 1 & $y, R_{x}$ & $Y z$ \\
\hline
\end{tabular}


identified as: $p_{z}, \mathrm{a}_{1} ; p_{x}, \mathrm{~b}_{1}$ and $p_{y}, \mathrm{~b}_{2}$ (N.B. Lower-case letters are used to represent the irreducible representations).

$\underline{\text { Step 3 }}$. Identification of the symmetries of the LGOs for the $\mathrm{H}$ atoms of $\mathrm{H}_{2} \mathrm{O}$. To achieve this, the internal coordinates for the $\sigma$ bonds $\left(\sigma_{1}\right.$ and $\sigma_{2}$ ) in Figure 1 must be considered. In the four examples examined in this paper, the orbitals of the $\mathrm{H}$ atoms in the molecular orbital diagrams are referred to as "ligand group orbitals" which are symmetry - adapted $\mathrm{H}$ atomic orbitals. The reducible representations for the LGOs are given by the number of internal coordinates $(\sigma)$ that do not move when each of the different symmetry operations is applied.

\begin{tabular}{c|c|c|c|c}
$\mathbf{C}_{2 \mathrm{v}}$ & $\mathbf{E}$ & $\mathbf{C}_{\mathbf{2}}$ & $\sigma_{\mathrm{v}}(\mathbf{x z})$ & $\sigma_{\mathbf{v}}(\mathbf{y z})$ \\
\hline$\Gamma_{\text {red }}$ & 2 & 0 & 0 & 2
\end{tabular}

$\mathrm{a}_{\mathrm{a} 1}=1 / 4[(1 \times 2 \times 1)+(1 \times 0 \times 1)+(1 \times 0 \times 1)+(1 \times 2 \times 1)]=1$

$\mathrm{a}_{\mathrm{a} 2}=1 / 4[(1 \times 2 \times 1)+(1 \times 0 \times 1)+(1 \times 0 \times-1)+(1 \times 2 \times-1)]=0$

$a_{b 1}=1 / 4[(1 \times 2 \times 1)+(1 \times 0 \times-1)+(1 \times 0 \times 1)+(1 \times 2 \times-1)]=0$

$\mathrm{a}_{\mathrm{b} 2}=1 / 4[(1 \times 2 \times 1)+(1 \times 0 \times-1)+(1 \times 0 \times-1)+(1 \times 2 \times 1)]=1$

Thus, the symmetries of the LGOs for $\mathrm{H}_{2} \mathrm{O}$ are $\mathrm{a}_{1}+\mathrm{b}_{2}$.

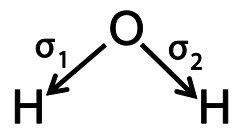

Figure 1. Internal coordinates of $\mathrm{H}_{2} \mathrm{O}$

Step 4. Construction of the energy level diagram for $\mathrm{H}_{2} \mathrm{O}$. Figure 2 illustrates the $\mathrm{MO}$ energy diagram for $\mathrm{H}_{2} \mathrm{O}$. The students know that linear combinations of the central atom atomic orbitals and the LGOs have to be accomplished with orbitals with the same irreducible representations and that, in the four examples being considered in this paper, the orbitals have the energy requirements to combine. For more advanced students, some papers that deal with more detailed energy calculations are suggested. ${ }^{7,8}$ (Comment: it should be noted it is an approximation to state that $a_{1}$ and $b_{2}$ ligand orbitals have the same energies.)

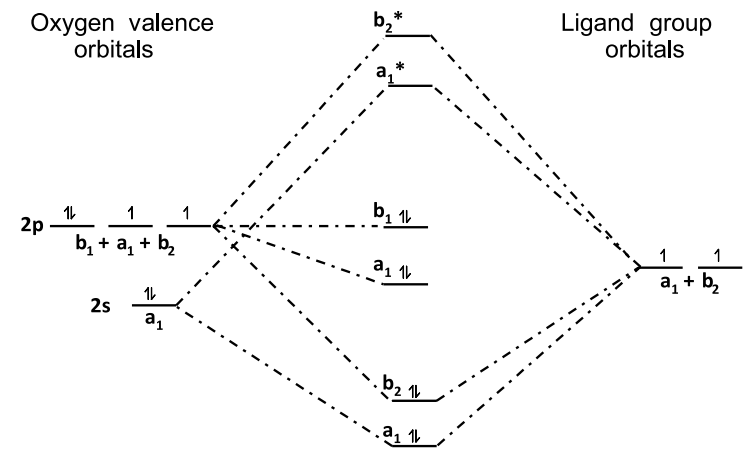

Figure 2. Molecular orbital energy diagram for $\mathrm{H}_{2} \mathrm{O}$

Considering the number of electrons in the various orbitals:

Bond order of $\mathrm{H}_{2} \mathrm{O}=1 / 2(4-0)=2$

Bond order of $\mathrm{O}-\mathrm{H}=2 / 2=1$

We use the approximation that two orbitals combine to form two new orbitals, such that the $a_{1}$ orbital which originates from the $p_{z}$ oxygen orbital is represented as shown above and not as a linear combination of all the $a_{1}$ orbitals in the molecule. This orbital is lowered in energy as a result of interaction with other orbitals of the same symmetry.

\section{Example 2: $\mathrm{NH}_{3}$}

$\underline{\text { Step } 1}$. The point group of $\mathrm{NH}_{3}$ is $\mathrm{C}_{3 \mathrm{v}}$
Step 2. The symmetries of the $2 s$ and $2 p$ orbitals of $\mathrm{N}$ are $\mathrm{a}_{1}$ and $\mathrm{a}_{1}$ $+\mathrm{e}$, respectively.

Step 3. The symmetries of the LGOs are represented as three vectors along the $\mathrm{NH}$ bond axes:

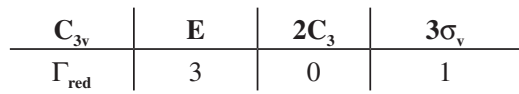

$\mathrm{a}_{\mathrm{a} 1}=1, \mathrm{a}_{\mathrm{a} 2}=0, \mathrm{a}_{\mathrm{e}}=1$

Thus, the symmetries of the LGOs for $\mathrm{NH}_{3}$ are $\mathrm{a}_{1}+\mathrm{e}$. Step 4. The MO energy diagram for $\mathrm{NH}_{3}$ is shown in Figure 3.

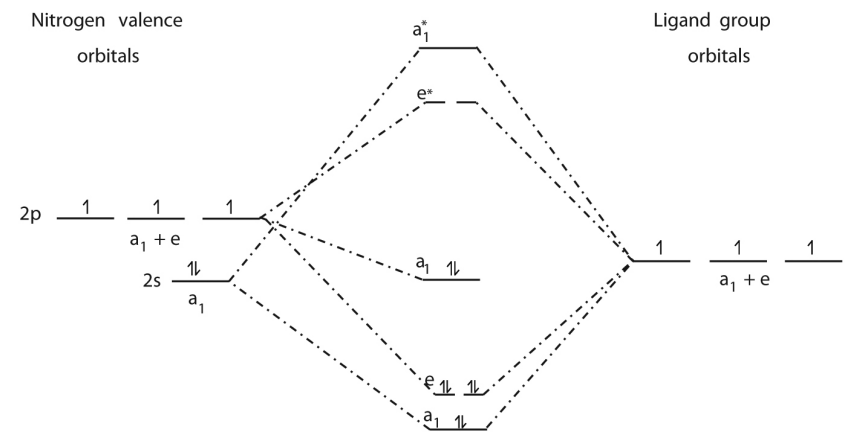

Figure 3. Molecular orbital energy diagram for $\mathrm{NH}_{3}$

The energy of the central $a_{1}$ orbital is lowered by interactions with other orbitals of the same symmetry in the approximation that we are using, as explained above.

Bond order of $\mathrm{NH}_{3}=1 / 2(6-0)=3$

Bond order of N-H:1

\section{Example 3: $\mathbf{B H}_{3}$}

Step 1. The point group of $\mathrm{BH}_{3}$ is $\mathrm{D}_{3 \mathrm{~h}}$.

$\underline{\text { Step } 2}$. The symmetries of the $2 \mathrm{~s}$ and $2 \mathrm{p}$ orbitals of $\mathrm{B}$ are $\mathrm{a}_{1}$ ' and $\mathrm{e}^{\prime}$ $+\mathrm{a}_{2}$ ", respectively.

$\underline{\text { Step } 3}$. The symmetries of the LGOs are given by:

\begin{tabular}{c|c|c|c|c|c|c}
$\mathbf{D}_{\mathbf{3 h}}$ & $\mathrm{E}$ & $2 \mathrm{C}_{3}$ & $3 \mathrm{C}_{2}$ & $\sigma_{\mathrm{h}}$ & $2 \mathrm{~S}_{3}$ & $3 \sigma_{\mathrm{v}}$ \\
\hline Гred & 3 & 0 & 1 & 3 & 0 & 1
\end{tabular}

$\mathrm{a}_{\mathrm{a} 1},=1, \mathrm{a}_{\mathrm{e}}=1$

Therefore, the symmetries of the LGOs for $\mathrm{BH}_{3}$ are $\mathrm{a}_{1}$ ' $+\mathrm{e}$ '. Step 4. The energy level diagram for $\mathrm{BH}_{3}$ is shown in Figure 4.

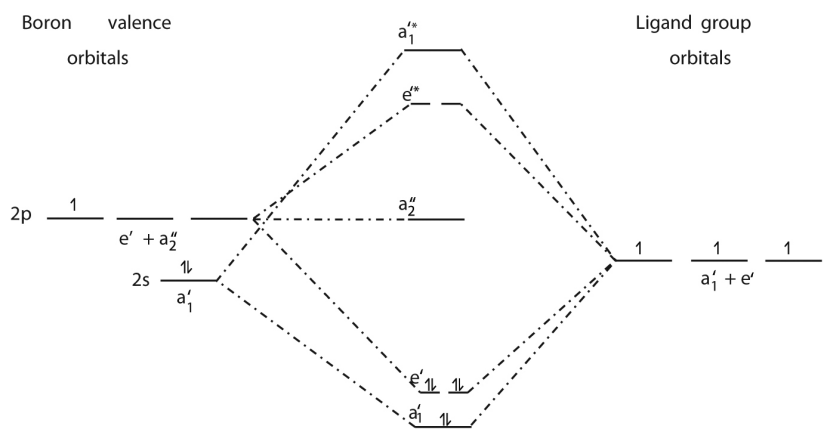

Figure 4. Molecular orbital energy diagram for $\mathrm{BH}_{3}$

Bond order of $\mathrm{BH}_{3}=1 / 2(6-0)=3$

Bond order of B-H: 1

(N.B. Chemically, $\mathrm{BH}_{3}$ is actually a H-bridged dimer, $\mathrm{B}_{2} \mathrm{H}_{6}$, but it is easier for the students to understand the approach for the simpler $\mathrm{BH}_{3}$ species.) 
At this stage, we ask the students what is required for $\mathrm{NH}_{3}(\mathrm{a}$ Lewis base) and $\mathrm{BH}_{3}$ (a Lewis acid) to react together to form the 1:1 adduct $\mathrm{NH}_{3}-\mathrm{BH}_{3}$. The answer is that the $\mathrm{BH}_{3}$ molecule must distort from $\mathrm{D}_{3 \mathrm{~h}}$ to $\mathrm{C}_{3 \mathrm{v}}$ symmetry, so that its LUMO orbitals (which are empty and higher in energy) will have the same symmetries as do the HOMO orbitals (which are full and lower in energy) of $\mathrm{NH}_{3}$. Only then, will it be possible for the LUMO and HOMO orbitals to combine linearly to form two new molecular orbitals thereby producing the adduct (Figure 5).

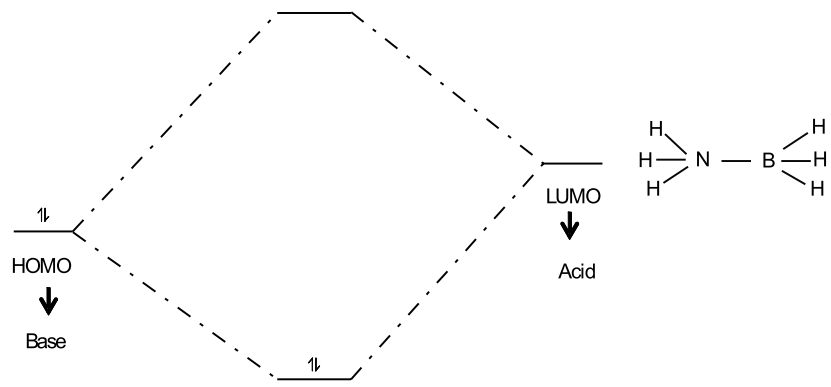

Figure 5. Acid and base coordination interaction

\section{Example 4: $\mathrm{SiH}_{4}$}

Step 1. The point group of $\mathrm{SiH}_{4}$ is $\mathrm{T}_{\mathrm{d}}$.

Step 2. The symmetries of the $3 \mathrm{~s}$ and 3 p orbitals of $\mathrm{Si}$ are $\mathrm{a}_{1}$ and $\mathrm{t}_{2}$, respectively.

Step 3 . The symmetries of the LGOs are given by:

\begin{tabular}{c|c|c|c|c|c}
$\mathbf{T}_{\mathbf{d}}$ & $\mathbf{E}$ & $\mathbf{8 C}_{\mathbf{3}}$ & $\mathbf{3 C}_{\mathbf{2}}$ & $\mathbf{6 S}_{4}$ & $\mathbf{6 \sigma}_{\mathbf{d}}$ \\
\hline$\Gamma_{\text {red }}$ & 4 & 1 & 0 & 0 & 2
\end{tabular}

$\mathrm{a}_{\mathrm{a} 1}=1, \mathrm{a}_{\mathrm{t} 2}=1$

Therefore, the symmetries of the LGOs for $\mathrm{SiH}_{4}$ are $\mathrm{a}_{1}+\mathrm{t}_{2}$. Step 4. The MO energy level diagram for $\mathrm{SiH}_{4}$ is shown in Figure 6.

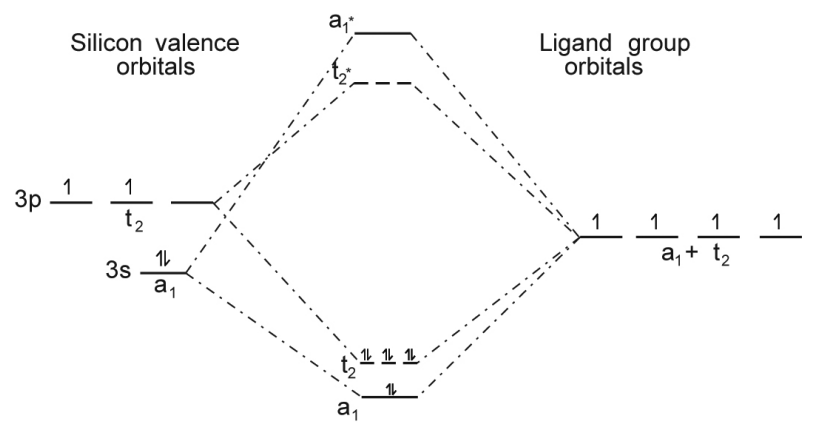

Figure 6. Molecular orbital energy diagram for $\mathrm{SiH}_{4}$

Bond order of $\mathrm{SiH}_{4}=1 / 2(8-0)=4$

Bond order of Si-H:1

The students have now been introduced to the stepwise use of group theory in MO theory for some simple polyatomic molecules where the next step is to apply the same approach to transition-metal complexes. From their earlier studies of crystal field theory, the students know that the $d$ orbitals for an octahedral $\mathrm{ML}_{6}$ molecule are not degenerate and that the molecular point group is $\mathrm{O}_{\mathrm{h}}$. After applying the same four-step approach described above, the LGOs for the $\sigma$ bonds of an $\mathrm{ML}_{6}$ molecule can be shown to be $\mathrm{a}_{1 \mathrm{~g}}+\mathrm{e}_{\mathrm{g}}+$ $\mathrm{t}_{1 \mathrm{u}}$. The symmetries of the central metal atom orbitals are: $\mathrm{t}_{2 \mathrm{~g}}$ and $\mathrm{e}_{\mathrm{g}}$ [for the (n-1) $d$ orbitals from the $4^{\text {th }}$ column of the $\mathrm{O}_{\mathrm{h}}$ character table where the symmetries of the binary products of vectors appear], $a_{1 g}$ $(\mathrm{n} s)$ and $\mathrm{t}_{1 \mathrm{u}}(\mathrm{n} p)$. The MO energy diagram can then constructed, as is given in most modern inorganic chemistry textbooks. ${ }^{1-6}$ We believe that following this introduction to the application of group theory in generating MO energy diagrams, the students will be in a better position to understand the symmetries of $\pi$ bonds and will also be able to handle other geometries of transition-metal complexes, i.e., $\mathrm{T}_{\mathrm{d}}$ (tetrahedral) and $\mathrm{D}_{4 \mathrm{~h}}$ (square planar), in which the internal coordinates for both $\sigma$ and $\pi$ bonds are involved.

\section{CONCLUSIONS}

In order to render our group theoretical method for producing MO energy diagrams easier for undergraduate students to follow, we have constructed the following stepwise general approach:

$\underline{\text { Step } 1 .}$. Identify the point group symmetry of the molecule

Step 2. Determine the symmetries of the valence orbitals of the central atom from the character table

Step 3. Find the symmetries of the LGOs

Step 4. Construct the MO energy level diagram .

This algorithm is entirely consistent with Taber's well-known pedagogical approach to chemical education. ${ }^{9}$

\section{ACKNOWLEDGEMENTS}

I. M. Baibich thanks CNPq (Brazil) for financial support. I. S. Butler gratefully acknowledges a NSERC InterAmerica Collaborative Grant for travel assistance between Canada and Brazil. We thank S. Wolke for the Figures.

\section{REFERENCES}

1. Douglas, B.; McDaniel, D.; Alexander, J.; Concepts and Models of Inorganic Chemistry, $3^{\text {rd }}$ ed., John Wiley \& Sons: New York, 1997.

2. Huheey, J. E.; Inorganic Chemistry, $4^{\text {th }}$ ed., Harper \& Row publ.: New York, 1993.

3. Butler, I. S.; Harrod, J. F.; Inorganic Chemistry, Principles and Applications, The Benjamin/Cummings Publishing Company: New York, 1989.

4. Cotton, F. A.; Wilkinson, G.; Advanced Inorganic Chemistry, $6^{\text {th }}$ ed., John Wiley \& Sons: New York, 1999.

5. Shriver, D. F.; Atkins, P. W.; Langford, C. H.; Inorganic Chemistry, $4^{\text {th }}$ ed., Oxford University Press: Oxford, 2004.

6. Cotton, F. A.; Chemical Applications of Group Theory, WileyInterscience: New York, 1990.

7. Harrison, J. F.; Lawson, D. B.; J. Chem. Educ. 2005, 82, 1205.

8. Cass, M. E.; Hollingsworth, W. E.; J. Chem. Educ. 2004, 81, 997.

9. Taber, K. S.; Chemical Education: Research and Practice in Europe 2001, 2, 123. 